\title{
Knockdown of long non-coding RNA LINC00152 increases cisplatin sensitivity in ovarian cancer cells
}

\author{
HANXUE ZOU and HONGXIA LI
}

\begin{abstract}
Department of Obstetrics and Gynecology, Beijing Shijitan Hospital of Capital Medical University, Beijing 100038, P.R. China
\end{abstract}

Received February 14, 2019; Accepted August 30, 2019

DOI: $10.3892 /$ etm.2019.8066

\begin{abstract}
Drug resistance severely limits the effectiveness of chemotherapeutic treatment in ovarian cancer. The present study aimed to investigate the role of long non-coding RNA LINC00152 (LINC00152) in the cisplatin resistance of ovarian cancer. The expression level of LINC00152 was significantly increased in the ovarian cancer $\mathrm{CoC} 1$ and $\mathrm{CoC} 1 / \mathrm{DDP}$ cell lines compared with the normal ovarian IOSE-80 cell line. To further investigate the function of LINC00152, small interfering RNAs (siRNAs) targeting LINC00152 were transfected into COC1 and COC1/DDP cells, which were subsequently treated with varying concentrations of cisplatin. The results revealed that LINC00152 silencing increased the apoptotic rates and enhanced the chemosensitivity of $\mathrm{CoC} 1$ and $\mathrm{CoC} 1 / \mathrm{DDP}$ cells to cisplatin. Furthermore, downregulation of LINC00152 significantly decreased Bcl-2, and increased Bax and cleaved caspase-3 expression levels. Additionally, LINC00152 silencing decreased the expression of multidrug resistance-associated gene 1 (MDR1), multidrug resistance-associated protein 1 (MRP1) and glutathione S-transferase $\pi$ (GST $\pi$ ). Collectively, the data demonstrated that LINC00152 knockdown increased the chemosensitivity of epithelial ovarian cancer cells to cisplatin by increasing apoptosis and decreasing the expression levels of MDR1, MRP1 and GST $\pi$.
\end{abstract}

\section{Introduction}

Ovarian cancer is a life-threatening malignancy that has high rates of incidence and mortality $(1,2)$. As one of the most effective and commonly used chemotherapeutic drugs, cisplatin is used to treat a number of cancer types. Treatment with cisplatin results in the formation of DNA adducts and causes

\footnotetext{
Correspondence to: Dr Hongxia Li, Department of Obstetrics and Gynecology, Beijing Shijitan Hospital of Capital Medical University, 10 Tieyi Road, Haidian, Beijing 100038, P.R. China

E-mail: hongxiali323@163.com
}

Key words: ovarian cancer, long non-coding RNA LINC00152, cisplatin resistance, $\mathrm{COC} 1$ cells, $\mathrm{COC} 1 / \mathrm{DDP}$ cells
DNA damage in tumor cells through the irreversible insertion of DNA bases (3); this prevents tumor cell DNA replication and activates cell death $(3,4)$. In previous years, cisplatin has attracted extensive attention $(4,5)$. However, ovarian cancer cells frequently develop cisplatin resistance during treatment, which severely limits the efficacy of the drug and is the primary cause of treatment failure (6). Therefore, to enhance the sensitivity of ovarian cancer cells to cisplatin it is first necessary to investigate the mechanism of drug resistance.

Long non-coding RNAs (lncRNAs) are a class of transcripts $>200$ nucleotides in length with no apparent protein-coding capacity (7). The altered expression of lncRNAs has been demonstrated to positively and negatively regulate various biological and pathological processes, including cellular proliferation, migration, invasion, differentiation, apoptosis and carcinogenesis $(8,9)$. Numerous studies have focused on the role of IncRNAs in cancer cell drug resistance; lncRNA colon cancer-associated transcript-1 contributed to cisplatin resistance in the non-small cell lung cancer cell line A549/DDP by downregulating the expression of microRNA (miR)-130a-3p (10). In addition, knockdown of lncRNA nuclear enriched abundant transcript 1 significantly increased dexamethasone sensitivity in multiple myeloma cell lines (11). IncRNA LINC00152 (LINC00152) has been suggested to have an oncogenic function in various types of cancer, and a previous study revealed that the downregulation of LINC00152 increased the rate of apoptosis and suppressed tumor growth in ovarian cancer by targeting miR-125b (12). However, the role of LINC00152 in the development of ovarian cancer remains unclear, and few studies have evaluated the effect of LINC00152 in chemotherapy-resistant ovarian cancer.

In the present study, the data demonstrated that silencing LINC00152 promoted apoptosis and enhanced the cisplatin sensitivity of ovarian cancer cells.

\section{Materials and methods}

Cell culture. The human normal ovarian cells line IOSE-80, ovarian adenocarcinoma cell line COC1 and its cisplatin-resistant variant COC1/DDP were obtained from the China Center for Type Culture Collection. The cells were cultured in RPMI-1640 supplemented with $10 \%$ fetal bovine serum (Gibco; Thermo Fisher Scientific, Inc.,) at $37^{\circ} \mathrm{C}$ in a 
humidified atmosphere $\left(5 \% \mathrm{CO}_{2}\right)$. $\mathrm{COC} 1$ and $\mathrm{COC} 1 / \mathrm{DDP}$ cells were treated with different doze of cisplatin $24 \mathrm{~h}$, as described previously (13-15). Then cells were then collected for further experiments.

Reverse transcription-quantitative polymerase chain reaction $(R T-q P C R)$. Total RNA was extracted from cells using TRIzol ${ }^{\circledR}$ reagent (Invitrogen; Thermo Fisher Scientific, Inc.,) according to the manufacturer's protocol. cDNA was generated using the TaqMan Reverse Transcription Kit (Takara Biotechnology Co., Ltd.) and PCR reactions were subsequently performed using the Perfect Real Time SYBR ${ }^{\circledR}$ Premix Ex Taq ${ }^{\mathrm{TM}}$ kit (Takara Biotechnology Co., Ltd.) with the ABI 7500 thermocycler (Thermo Fisher Scientific, Inc.). The thermocycling conditions were as follows: Initial denaturation at $95^{\circ} \mathrm{C}$ for $5 \mathrm{~min}$. Amplification cycle consists of three steps; a denaturation step at $95^{\circ} \mathrm{C}$ for $30 \mathrm{sec}$, an annealing step at $60^{\circ} \mathrm{C}$ for $45 \mathrm{sec}$ and a final extension of $10 \mathrm{~min}$ at $72^{\circ} \mathrm{C}$. U6 was used as normalization control for LINC00152 expression. GAPDH was used as an internal control for mRNAs multi-drug resistance gene 1 (MDR1), multidrug resistance-associated protein 1 (MRP1) and glutathione S-transferase $\pi$ (GST $\pi$ ). The results of the relative expression levels of RNAs were analyzed using the $2^{-\Delta \Delta \mathrm{Cq}}$ method (16). Independent experiments were repeated 3 times. The primers used were as follows: LINC00152 forward, 5'-TGAGAATGAAGGCTGAGGTGT-3'; LINC00152 reverse, 5'-GCAGCGACCATCCAGTCATT-3'; U6 forward, 5'-CTC GCTTCGGCAGCACA-3'; U6 reverse 5'-AACGCTTCAGGA ATTTGCGT-3'; MDR1 forward, 5'-ATTGCTCACCGCCTG TCCACC-3'; MDR1 reverse, 5'-TGCTGATGCGTGCCA TGCTCC-3'; MRP1 forward, 5'-CGTGTTGGTCTCTGT GTTCC TG-3'; MRP1 reverse, 5'-AGAAAGATGCTCTCT GGGTTTG-3'; GST $\pi$ forward, 5'-TGGGCATCTGAAGCC TTTTG-3'; GST $\pi$ reverse, 5'-GATCTGGTCACCCACGAT GAA-3'; GAPDH forward, 5'-GGAGCGAGATCCCTCCAA AAT-3'; and GAPDH reverse 5'-GGCTGTTGTCATACTTCT CATGG-3'.

Transfection. Small interfering RNAs (siRNAs) targeting LINC00152 (si-1-LINC00152 and si-2-LINC00152) and an appropriate negative control (si-NC) were transfected into COC1 and COC1/DDP cells. All siRNAs were designed and synthesized by Guangzhou RiboBio Co., Ltd. Cells were cultured in 6-well plates to $70-80 \%$ confluence, and the siRNAs $(100 \mathrm{nM})$ were transfected into the cells using Lipofectamine ${ }^{\circledR}$ 2000 reagent (Invitrogen; Thermo Fisher Scientific, Inc.,) according to the manufacturer's protocol. Subsequent experiments were performed $48 \mathrm{~h}$ post-transfection.

Cell Counting Kit-8 (CCK-8) assay. The CCK-8 assay was used to assess cell proliferation capacity. Cells were seeded into 96 -well plates $\left(5 \times 10^{3}\right.$ cells/well) and incubated for $24 \mathrm{~h}$. COC1 cells were treated with $0,1,2,4,8,16$ or $32 \mu \mathrm{g} / \mathrm{ml}$ cisplatin, and COC1/DDP cells were treated with $0,4,8,16$, 32,64 or $128 \mu \mathrm{g} / \mathrm{ml}$ cisplatin for a further $24 \mathrm{~h}$. CCK-8 reagent (10 $\mu \mathrm{l}$ ) was then added to each well for an additional $2 \mathrm{~h}$. Absorbance was measured at $450 \mathrm{~nm}$ and the percentage of viable cells was calculated (normalized to the control group). A total of 4 wells for each concentration were examined, and the experiments were performed in triplicate.
Flow cytometric analysis of apoptosis. Cells were treated with cisplatin for $24 \mathrm{~h}$ and apoptosis was analyzed using an Annexin V-fluorescein isothiocyanate (FITC)/propidium iodide (PI) flow cytometry assay kit (BD Biosciences) according to the manufacturer's protocol. Briefly, cells were collected and fixed in pre-cooled $70 \%$ ethanol at $4^{\circ} \mathrm{C}$ overnight. The cells were resuspended in $300 \mu \mathrm{l}$ cold binding buffer, and labeled with $5 \mu \mathrm{l}$ Annexin V-FITC $(20 \mu \mathrm{g} / \mathrm{ml})$ for $10 \mathrm{~min}$ in the dark at room temperature. Following the addition of $5 \mu 1 \mathrm{PI}$ (50 $\mu \mathrm{g} / \mathrm{ml})$ and $200 \mu \mathrm{l}$ binding buffer, the samples were incubated at room temperature in the dark for an additional $5 \mathrm{~min}$. Apoptotic cells were quantified using the FACSCalibur ${ }^{\mathrm{TM}}$ flow cytometer (BD Biosciences) and data were analyzed using BD Accuri $^{\text {TM }}$ C6 (BD Biosciences). The experiments were independently repeated 3 times.

Western blot analysis. Following cisplatin treatment for $24 \mathrm{~h}$, the cells were harvested and total proteins were obtained using RIPA lysis buffer (Beyotime Institute of Biotechnology). Protein concentration was subsequently determined using the BCA method (Beyotime Institute of Biotechnology). The proteins (30 $\mu \mathrm{g} /$ lane) were separated using $10 \%$ SDS-PAGE gel and subsequently transferred to PVDF membranes (EDM Millipore). Following blocking with 5\% milk for $2 \mathrm{~h}$ at room temperature, the membranes were incubated overnight at $4^{\circ} \mathrm{C}$ with the following primary antibodies: Anti-Bcl-2 (1:1,000; cat. no. 3498; Cell Signaling Technology, Inc.), anti-Bax (1:1,000; cat. no. 5023; Cell Signaling Technology, Inc.), anti-caspase-3 (1:500; cat. no. 14220; Cell Signaling Technology, Inc.), anti-cleaved-caspase-3 (1:500; cat. no. 9579; Cell Signaling Technology, Inc.) and GAPDH (1:2,000; cat. no. MAB374; EMD Millipore; Merck KGaA). The membranes were then incubated with the corresponding horseradish peroxidase-conjugated secondary antibodies mouse anti-rabbit (1:10,000; cat. no. sc-2357; Santa Cruz Biotechnology, Inc.), rabbit anti-mouse (1:10,000; cat. no. sc-358914; Santa Cruz Biotechnology, Inc.) at room temperature for an additional $2 \mathrm{~h}$, and protein expression was detected using an ECL detection reagent (EMD Millipore; Merck KGaA). Protein levels were normalized to that of GAPDH and the experiments were performed in triplicate. Quantification was carried out using ImageJ software (version 1.43; National Institutes of Health).

Statistical analysis. SPSS 17.0 software was used to conduct all statistical analyses (SPSS, Inc). The data are presented as the mean \pm standard error of the mean and each experiment was repeated $\geq 3$ times. The data were analyzed using the Students t-test or one-way analysis of variance followed by Dunnett's post-hoc test or Tukey's test. $\mathrm{P}<0.05$ was considered to indicate a statistically significant difference.

\section{Results}

Expression level of LINC00152 is upregulated in epithelial ovarian cancer cells. In the present study, the level of LINC00152 expression was detected in COC1 and COC1/DDP ovarian cancer cell lines, and in normal ovarian cells (IOSE-80). As demonstrated in Fig. 1A, LINC00152 expression level was significantly increased in the ovarian cancer cells compared 
A



B $\operatorname{coc} 1$

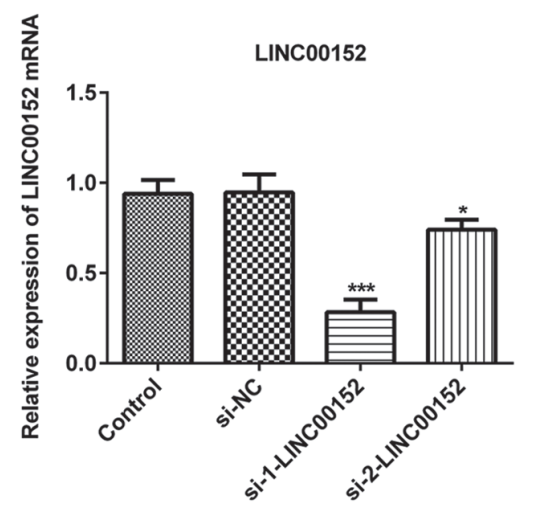

C COC1/DDP

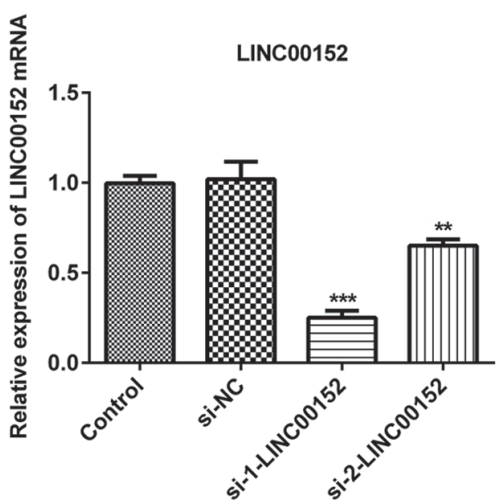

Figure 1. Expression level of LINC00152 is upregulated in ovarian cancer cells. (A) RT-qPCR was used to detect the expression level of LINC00152 in IOSE-80, COC1 and COC1/DDP cell lines. (B and C) siRNA (si-1-LINC00152 and si-2-LINC00152) and the negative control (si-NC) were transfected into (B) $\mathrm{COC} 1$ and (C) COC1/DDP cells. At $48 \mathrm{~h}$ post-transfection, LINC00152 expression levels were detected using RT-qPCR. ${ }^{*} \mathrm{P}<0.05,{ }^{* *} \mathrm{P}<0.01$ and ${ }^{* * * *} \mathrm{P}<0.001$ vs. IOSE-80 or si-NC. RT-qPCR, reverse transcription-quantitative polymerase chain reaction; siRNA, small interfering RNA; NC, negative control.

A

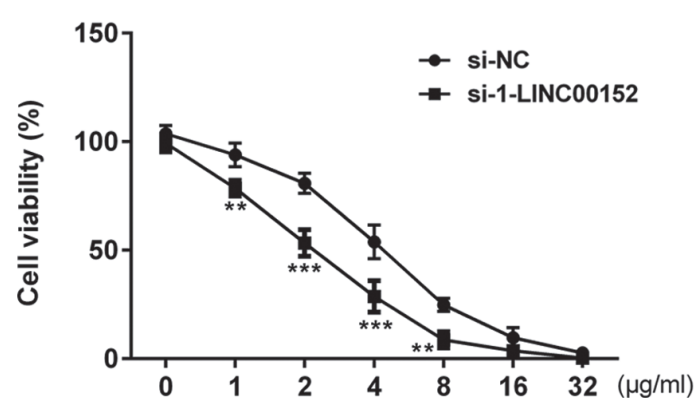

B

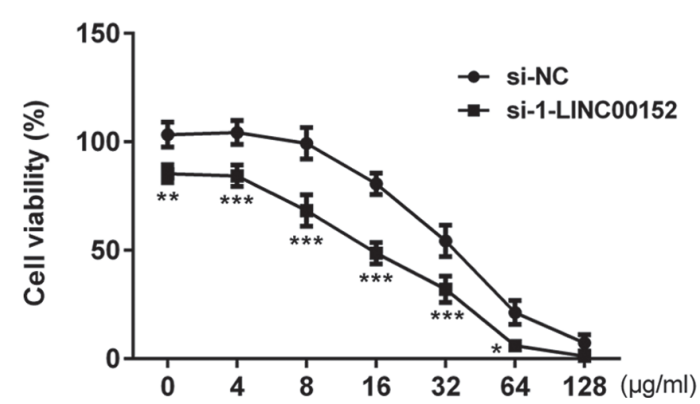

Figure 2. Effect of LINC00152 knockdown on cisplatin sensitivity. (A) At $24 \mathrm{~h}$ post-transfection with si-1-LINC00152 or si-NC, COC1 cells were treated with $0,1,2,4,8,16$ or $32 \mu \mathrm{g} / \mathrm{ml}$ cisplatin for a further $24 \mathrm{~h}$, and cell viability was assessed using the CCK-8 assay. (B) At $24 \mathrm{~h}$ post-transfection with si-1-LINC00152 or si-NC, COC1/DDP cells were treated with $0,4,8,16,32,64$ or $128 \mu \mathrm{g} / \mathrm{ml}$ cisplatin for a further $24 \mathrm{~h}$, and viability was assessed using the CCK-8 assay. ${ }^{*} \mathrm{P}<0.05,{ }^{* *} \mathrm{P}<0.01$ and ${ }^{* * *} \mathrm{P}<0.001$ vs. si-NC. CCK-8, Cell Counting Kit-8; si, small interfering RNA; NC, negative control.

with the normal ovarian cells. Furthermore, LINC00152 expression levels in COC1/DDP cisplatin-resistant cells were markedly increased compared with the cisplatin-sensitive COC1 cells (Fig. 1A). To further investigate the role of LINC00152 in ovarian cancer cells, siRNAs (si-1-LINC00152 and si-2-LINC00152) and the negative control (si-NC) were transfected into COC1 and COC1/DDP cells. Transfection efficiency was detected using RT-qPCR $48 \mathrm{~h}$ post-transfection. The results demonstrated that the inhibitory effect of si-1-LINC00152 on LINC00152 expression level was improved compared with that of si-2-LINC00152 in the COC1 (Fig. 1B) and COC1/DDP cells (Fig. 1C).

LINC00152 knockdown enhances the sensitivity of ovarian cancer cells to cisplatin. To additionally investigate the effects of LINC00152 knockdown on cisplatin resistance, LINC00152 knockdown cells were treated with a concentration gradient of cisplatin, and the levels of proliferation were assessed using the CCK- 8 assay $24 \mathrm{~h}$ after treatment. As indicated in the Fig. 2, the viability of si-1-LINC00152-transfected COC1 cells was significantly decreased compared with that of the si-NC-transfected COC1 cells. A similar effect was observed in COC1/DDP cells. At a cisplatin concentration of 4 or
$32 \mu \mathrm{g} / \mathrm{ml}$, the viability of COC1 and COC1/DDP cells was close to $50 \%$, respectively (Fig. 2), and these 2 concentrations were subsequently selected for subsequent investigation.

LINC00152-silencing promotes apoptosis in cisplatin-treated COC1 and COC1/DDP cells. To investigate the underlying mechanism of the LINC00152 knockdown-associated increase in cisplatin sensitivity, flow cytometric analyses were conducted to assess the rate of apoptosis in ovarian cancer cells. The results demonstrated that the apoptotic rate was significantly increased in the cisplatin-treated $\mathrm{COC} 1$ and COC1/DDP cells following LINC00152 knockdown (Fig. 3). Notably, si-1-LINC00152 transfection alone had no significant effect on the level of apoptosis in $\mathrm{COC1}$ cells (Fig. 3A and B); however, apoptosis was markedly promoted in the COC1/DDP cells (Fig. 3C and D). Furthermore, the western blot analysis results indicated that LINC00152 knockdown significantly decreased Bcl-2, and increased Bax and Cleaved caspase-3 expression levels in the cisplatin-treated (Fig. 4A) $\mathrm{COC} 1$ and (Fig. 4B) COC1/DDP cells. Again, si-1-LINC00152 transfection alone had no significant effect on the expression levels of these proteins in the $\mathrm{COC} 1$ cells (Fig. 4A), which was consistent with the results of the apoptosis assay. 

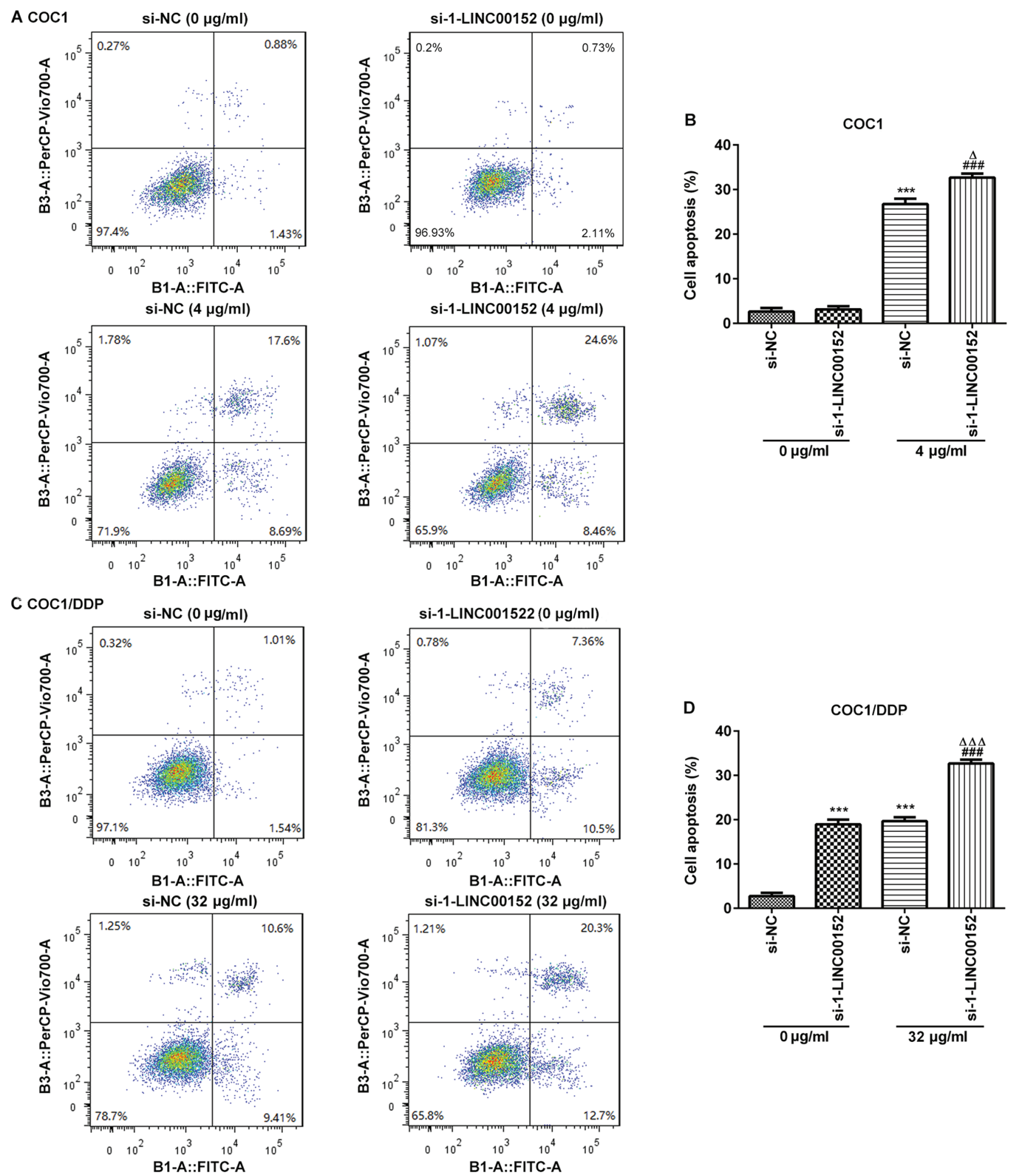

Figure 3. Effect of LINC00152 knockdown on apoptosis. At $24 \mathrm{~h}$ post-transfection with si-1-LINC00152 or si-NC, (A and B) COC1 and (C and D) COC1/DDP cells were treated with 4 or $32 \mu \mathrm{g} / \mathrm{ml}$ cisplatin, respectively. After $24 \mathrm{~h}$ of cisplatin treatment, apoptosis was analyzed by flow cytometry. ${ }^{* * *} \mathrm{P}<0.001 \mathrm{vs}$. si-NC $\left(0 \mu \mathrm{g} / \mathrm{ml}\right.$ cisplatin); ${ }^{\# \# \#} \mathrm{P}<0.001$ vs. si-1-LINC00152 (4 or $32 \mu \mathrm{g} / \mathrm{ml}$ cisplatin); ${ }^{\circ} \mathrm{P}<0.05$ and ${ }^{\Delta \Delta \Delta} \mathrm{P}<0.001$ vs. si-NC (4 or $32 \mu \mathrm{g} / \mathrm{ml}$ cisplatin). si, small interfering RNA; NC, negative control; FITC, fluorescein isothiocyanate.

LINC00152 silencing downregulates the expression level of MDR1, MRPI and GST $\pi$ in ovarian cancer cells. The mRNA expression levels of MDR1, MRP1 and GST $\pi$ were detected using RT-qPCR. LINC00152 silencing markedly decreased the level of MDR1, MRP1 and GST $\pi$ expression in $\mathrm{COC} 1$ (Fig. 5A) and COC1/DDP (Fig. 5B) cells following exposure to cisplatin. However, knockdown of LINC00152 alone did not affect mRNA expression levels in COC1 cells (Fig. 5A).

\section{Discussion}

At present, the most common treatments for ovarian cancer are surgery and chemotherapy. However, the level of drug resistance 
A coc1
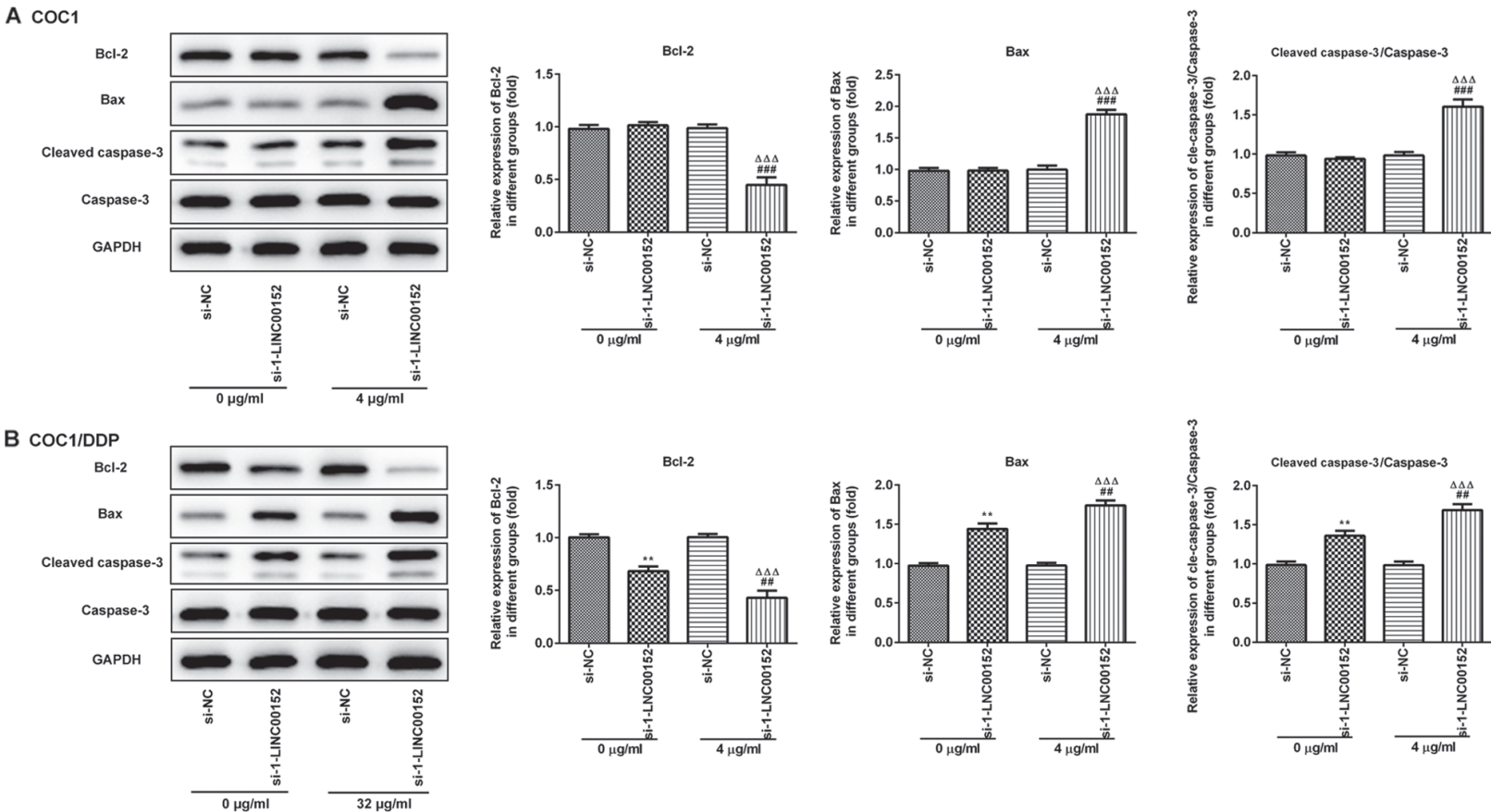

Figure 4. Effect of LINC00152 knockdown on the expression of apoptosis-associated proteins. si-1-LINC00152 or si-NC-transfected (A) COC1 and (B) COC1/DDP cells were treated with 4 or $32 \mu \mathrm{g} / \mathrm{ml}$ cisplatin, respectively, for $24 \mathrm{~h}$. Western blot analysis was used to determine Bcl-2, Bax, and cleaved caspase-3 expression levels. ${ }^{* *} \mathrm{P}<0.01$ vs. si-NC $\left(0 \mu \mathrm{g} / \mathrm{ml}\right.$ cisplatin); ${ }^{\# \#} \mathrm{P}<0.01$ and ${ }^{\# \# \#} \mathrm{P}<0.001$ vs. si-1-LINC00152 (4 or $32 \mu \mathrm{g} / \mathrm{ml}$ cisplatin); ${ }^{\Delta \Delta \Delta} \mathrm{P}<0.001$ vs. si-NC (4 or $32 \mu \mathrm{g} / \mathrm{ml}$ cisplatin). si, small interfering RNA; NC, negative control.

A

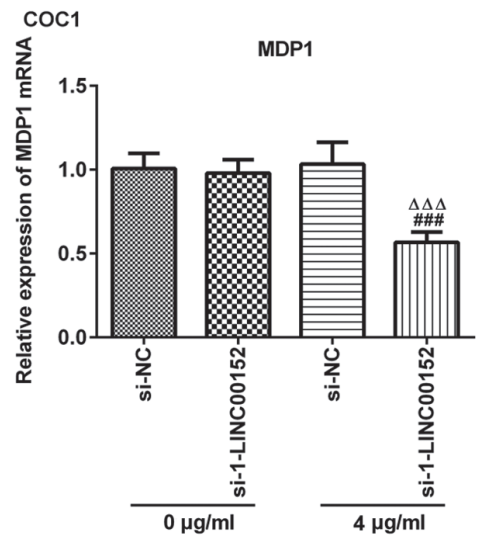

B $\quad$ COC1/DDP



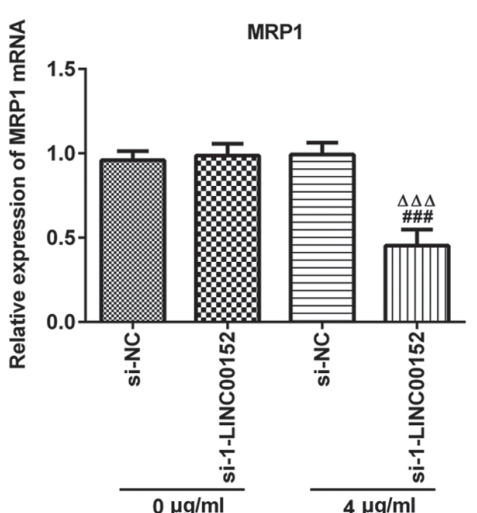
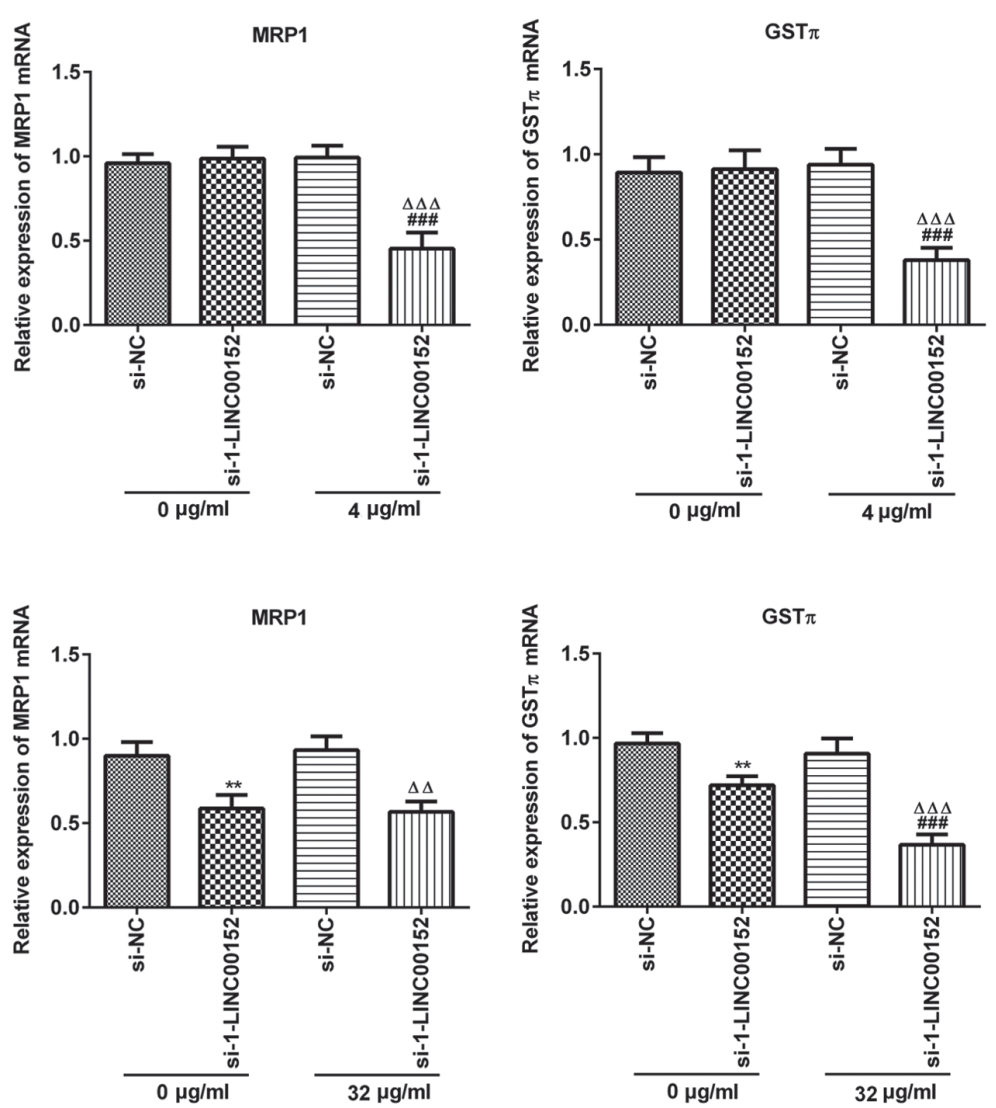

Figure 5. Effect of LINC00152 knockdown on the expression of multidrug resistance-associated genes. (A) COC1 and (B) COC1/DDP cells transfected with si-1-LINC00152 or si-NC were treated with 4 or $32 \mu \mathrm{g} / \mathrm{ml}$ cisplatin, respectively. At $24 \mathrm{~h}$ post-cisplatin treatment, reverse transcription-quantitative polymerase chain reaction analysis was performed to determine the expression levels of MDR1, MRP1 and GST $\pi$ mRNA. ${ }^{* *} \mathrm{P}<0.01 \mathrm{vs}$. si-NC $\left(0 \mu \mathrm{g} / \mathrm{ml}\right.$ cisplatin); ${ }^{* \# \#} \mathrm{P}<0.001$ vs. si-1-LINC00152 (4 or $32 \mu \mathrm{g} / \mathrm{ml}$ cisplatin); ${ }^{\Delta \Delta} \mathrm{P}<0.01$ and ${ }^{\Delta \Delta \Delta} \mathrm{P}<0.001$ vs. si-NC (4 or $32 \mu \mathrm{g} / \mathrm{ml}$ cisplatin). si, small interfering RNA; NC, negative control; MDR1, multidrug resistance-associated gene 1; MRP1, multidrug resistance-associated protein 1; GST $\pi$, glutathione S-transferase $\pi$. 
in cancer cells has a clear effect on patient prognosis $(6,17,18)$. Accumulating evidence has suggested that numerous lncRNAs are involved in the occurrence and development of ovarian cancer (19-21), and that they may considerably affect drug resistance (22). Xu et al (23) indicated that lncRNA EIBC was highly expressed in ovarian cancer tissues, and that the upregulation of EIBC promoted tumor growth and improved cisplatin resistance via inhibiting the $\mathrm{Wnt} / \beta$-catenin signaling pathway. Wang et al (24) demonstrated that the downregulation of Hox transcript antisense intergenic RNA significantly decreased the levels of cell proliferation and invasion, and reversed cisplatin resistance in SKOV-3CDDP/R cells. In addition, Zhang et al (25) indicated that Linc00312 promoted apoptosis and enhanced cisplatin sensitivity through the Bcl-2/Caspase-3 pathway in SKOV3/DDP cells. These studies indicated that lncRNAs have great potential in the treatment of cisplatin resistance. Another previous study suggested that LINC00152 confers oxaliplatin resistance by regulating the expression of miR-193a-3p, and that it may be an independent prognostic factor for colon cancer (26). Notably, a recent study by Chen et al (12) demonstrated that LINC00152 was upregulated in ovarian cancer tissues and cell lines, and that LINC00152 knockdown promoted apoptosis and inhibited tumor growth, suggesting a pro-cancer effect of LINC00152. To the best of our knowledge, in the present study, the sensitization effect of LINC00152 on cisplatin was evaluated for the first time in ovarian cancer cells. The results indicated that the expression level of LINC00152 was markedly increased in the COC1/DDP cisplatin-resistant cells compared with the cisplatin-sensitive COC1 and normal ovarian cells, concluding that LINC00152 knockdown enhanced cisplatin sensitivity in both COC1 and COC1/DDP cells.

Previous studies have revealed that the expression of multidrug resistance genes is closely associated with lncRNAs in tumors $(22,27)$; silencing of lncRNA metastasis-associated lung adenocarcinoma transcript decreased MDR1, MRP5 and prolow-density lipoprotein receptor-related protein 1 (LRP1) expression levels and reversed temozolomide resistance in glioblastoma cells (28). Additionally, downregulation of lncRNA X-inactive specific transcript inhibited GST $\pi$ expression, promoted apoptosis and increased the sensitivity of colorectal cancer cells to doxorubicin (29). The present study suggested that LINC00152 silencing promoted apoptosis and downregulated the levels of MDR1, MRP1 and GST $\pi$ expression in cisplatin-treated COC1 and COC1/DDP cells.

Notably, it was also identified that LINC00152 knockdown alone had no significant effect on apoptosis and the expression of drug resistance-associated genes (MDR1, MRP1 and GST $\pi$ ) in COC1 cells. Contrastingly, the data from the study by Chen et al (12) demonstrated that LINC00152 silencing significantly promoted apoptosis in the ovarian cancer SKOV3 and A2780 cell lines. This result is inconsistent with ours, potentially due to the selection of different cell lines. However, subsequent results from the present study indicated that LINC00152 knockdown markedly enhanced apoptosis in $\mathrm{COC1/DDP}$ cells with or without cisplatin treatment. Therefore, it was hypothesized that LINC00152 may serve a prominent role in the formation of cisplatin resistance in $\mathrm{COC} 1$ cells, and the acquisition of additional functions involved in this process.

There were certain limitations to the present study. Firstly, only the effect of LINC00152 silencing on the cisplatin resistance of $\mathrm{COC} 1$ and $\mathrm{COC} 1 / \mathrm{DDP}$ cells was investigated; whether the overexpression of LINC00152 has an effect on ovarian cancer was not explored. In addition, only $\mathrm{COC} 1$ and $\mathrm{COC1} / \mathrm{DDP}$ cells were used. Whether LINC00152 serves a role in other ovarian cancer cell lines is unknown. Future studies involving other cell lines and an animal model are required to confirm the results.

In conclusion, the present study revealed that the altered expression of LINC00152 may be associated with the cisplatin-resistance mechanisms of ovarian cancer cells. Knockdown of LINC00152 improved the chemosensitivity of epithelial ovarian cancer cells to cisplatin by increasing apoptosis and decreasing the expression levels of MDR1, MRP1 and GST $\pi$. Although future experiments are required for confirmation, the upregulation of LINC00152 may be involved in the formation of cisplatin resistance in COC1/DDP cells.

\section{Acknowledgements}

Not applicable.

Funding

No funding was received.

\section{Availability of data and materials}

The datasets used and/or analyzed during the present study are available from the corresponding author on reasonable request.

\section{Authors' contributions}

HZ and HL participated in data analysis and manuscript preparation. HZ performed the experiments and HL revised the manuscript.

\section{Ethics approval and consent to participate}

Not applicable.

\section{Patient consent for publication}

Not applicable.

\section{Competing interests}

The authors declare that they have no competing interests.

\section{References}

1. Mezzanzanica D: Ovarian cancer: A molecularly insidious disease. Chin J Cancer 34: 1-3, 2015

2. Siegel R, Naishadham D and Jemal A: Cancer statistics, 2013. CA Cancer J Clin 63: 11-30, 2013.

3. Galluzzi L, Senovilla L, Vitale I, Michels J, Martins I, Kepp O, Castedo M and Kroemer G: Molecular mechanisms of cisplatin resistance. Oncogene 31: 1869-1883, 2012.

4. Rancoule C, Guy JB, Vallard A, Ben Mrad M, Rehailia A and Magné N: 50th anniversary of cisplatin. Bull Cancer 104: $167-176,2017$.

5. Armstrong DK, Bundy B, Wenzel L, Huang HQ, Baergen R, Lele S, Copeland LJ, Walker JL and Burger RA; Gynecologic Oncology Group: Intraperitoneal cisplatin and paclitaxel in ovarian cancer. N Engl J Med 354: 34-43, 2006. 
6. Tomao F, Marchetti C, Romito A, Di Pinto A, Di Donato V, Capri O, Palaia I, Monti M, Muzii L and Benedetti Panici P: Overcoming platinum resistance in ovarian cancer treatment: From clinical practice to emerging chemical therapies. Expert Opin Pharmacother 18: 1443-1455, 2017.

7. Jarroux J, Morillon A and Pinskaya M: History, discovery, and classification of lncRNAs. Adv Exp Med Biol 1008: 1-46, 2017.

8. Wieczorek E and Reszka E: mRNA, microRNA and lncRNA as novel bladder tumor markers. Clin Chim Acta 477: 141-153, 2018.

9. Marchese FP, Raimondi I and Huarte M: The multidimensional mechanisms of long noncoding RNA function. Genome Biol 18: 206, 2017.

10. Hu B, Zhang $\mathrm{H}$, Wang Z, Zhang F, Wei $\mathrm{H}$ and Li L: LncRNA CCAT1/miR-130a-3p axis increases cisplatin resistance in non-small-cell lung cancer cell line by targeting SOX4. Cancer Biol Ther 18: 974-983, 2017.

11. Wu Y and Wang H: LncRNA NEAT1 promotes dexamethasone resistance in multiple myeloma by targeting miR-193a/MCL1 pathway. J Biochem Mol Toxicol 32: e22008, 2018.

12. Chen P, Fang X, Xia B, Zhao Y, Li Q and Wu X: Long noncoding RNA LINC00152 promotes cell proliferation through competitively binding endogenous miR-125b with MCL-1 by regulating mitochondrial apoptosis pathways in ovarian cancer. Cancer Med 7: 4530-4541, 2018.

13. Ma J, Yang J, Wang C, Zhang N, Dong Y, Wang C, Wang Y and Lin $\mathrm{X}$ : Emodin augments cisplatin cytotoxicity in platinum-resistant ovarian cancer cells via ROS-dependent MRP1 downregulation. Biomed Res Int 2014: 107671, 2014.

14. Zhang T, Guan M, Jin HY and Lu Y: Reversal of multidrug resistance by small interfering double-stranded RNAs in ovarian cancer cells. Gynecol Oncol 97: 501-507, 2005.

15. Wang F, Zhu Y, Fang S, Li S and Liu S: Effect of lanthanum chloride on tumor growth and apoptosis in human ovarian cancer cells and xenograft animal models. Exp Ther Med 16: 1143-1148, 2018.

16. Livak KJ and Schmittgen TD: Analysis of relative gene expression data using real-time quantitative PCR and the 2(-Delta Delta C(T)) method. Methods 25: 402-408, 2001.

17. Pogge von Strandmann E, Reinartz S, Wager U and Müller R: Tumor-Host cell interactions in ovarian cancer: Pathways to therapy failure. Trends Cancer 3: 137-148, 2017.

18. Kujawa KA and Lisowska KM: Ovarian cancer-from biology to clinic. Postepy Hig Med Dosw (Online) 69: 1275-1290, 2015 (In Polish).

19. Mitra R, Chen X, Greenawalt EJ, Maulik U, Jiang W, Zhao Z and Eischen CM: Decoding critical long non-coding RNA in ovarian cancer epithelial-to-mesenchymal transition. Nat Commun 8 : 1604,2017
20. Worku T, Bhattarai D, Ayers D, Wang K, Wang C, Rehman ZU, Talpur HS and Yang L: Long non-coding RNAs: The new horizon of gene regulation in ovarian cancer. Cell Physiol Biochem 44: 948-966, 2017.

21. Martini P, Paracchini L, Caratti G, Mello-Grand M, Fruscio R, Beltrame L, Calura E, Sales G, Ravaggi A, Bignotti E, et al: lncRNAs as novel indicators of patients' prognosis in stage I epithelial ovarian cancer: A retrospective and multicentric study. Clin Cancer Res 23: 2356-2366, 2017.

22. Xu J, Wu J, Fu C, Teng F, Liu S, Dai C, Shen R and Jia X: Multidrug resistant lncRNA profile in chemotherapeutic sensitive and resistant ovarian cancer cells. J Cell Physiol 233: 5034-5043, 2018.

23. Xu QF, Tang YX and Wang X: LncRNA EBIC promoted proliferation, metastasis and cisplatin resistance of ovarian cancer cells and predicted poor survival in ovarian cancer patients. Eur Rev Med Pharmacol Sci 22: 4440-4447, 2018.

24. Wang Y, Wang H, Song T, Zou Y, Jiang J, Fang L and Li P: HOTAIR is a potential target for the treatment of cisplatinresistant ovarian cancer. Mol Med Rep 12: 2211-2216, 2015.

25. Zhang C, Wang M, Shi C, Shi F and Pei C: Long non-coding RNA Linc00312 modulates the sensitivity of ovarian cancer to cisplatin via the Bcl-2/Caspase-3 signaling pathway. Biosci Trends 12: 309-316, 2018.

26. Yue B, Cai D, Liu C, Fang C and Yan D: Linc00152 Functions as a competing endogenous RNA to confer oxaliplatin resistance and holds prognostic values in colon cancer. Mol Ther 24: 2064-2077, 2016 .

27. Guo F, Cao Z, Guo $\mathrm{H}$ and Li S: The action mechanism of IncRNA-HOTAIR on the drug resistance of non-small cell lung cancer by regulating Wnt signaling pathway. Exp Ther Med 15: 4885-4889, 2018.

28. Li H, Yuan X, Yan D, Li D, Guan F, Dong Y, Wang H, Liu X and Yang B: Long non-coding RNA MALAT1 decreases the sensitivity of resistant glioblastoma cell lines to temozolomide. Cell Physiol Biochem 42: 1192-1201, 2017.

29. Zhu J, Zhang R, Yang D, Li J, Yan X, Jin K, Li W, Liu X, Zhao J, Shang W and Yu T: Knockdown of long non-coding RNA XIST inhibited doxorubicin resistance in colorectal cancer by upregulation of miR-124 and downregulation of SGK1. Cell Physiol Biochem 51: 113-128, 2018

This work is licensed under a Creative Commons Attribution-NonCommercial-NoDerivatives 4.0 International (CC BY-NC-ND 4.0) License. 